ScIDoC

International Journal of Dentistry and Oral Science (IJDOS)

ISSN: $2377-8075$

\title{
A Survey Of Knowledge and Clinical Consideration On Fiber Post For Restoration Of Endodontically Treated Tooth Among Undergraduate Dentistry Students
}

Research Article

Mohamed, Nusima ${ }^{1 *}$, Mohd Rasdi, Nurul Atiqah², Che Lah, Nur Fatin Izzati ${ }^{2}$, Ismail, Nor Azlina ${ }^{3}$

${ }^{1}$ Dental Lecturer, Prosthodontist, Department of Prosthodontics \& Conservative Dentistry, Universiti Sains Islam Malaysia (USIM), Kuala Lumpur, Malaysia.

${ }^{2}$ Undergraduate Students, Faculty of Dentistry, USIM, Kuala Lumpur, Malaysia.

${ }^{3}$ Dental Lecturer, Department of Prosthodontics \& Conservative Dentistry, Universiti Sains Islam Malaysia (USIM), Kuala Lumpur, Malaysia.

\section{Abstract}

Post is used to give sufficient retention for the restoration of endodontically treated teeth. Recently, there are many types of post including fiber post. It is preferred due to its lower modulus elasticity similar to dentine. In Malaysia, there is lack of study regarding the use of fiber post. This study was done using an online survey distributed to dentistry students in selected universities in Malaysia. Study aim to assess their knowledge and clinical consideration on fiber post descriptively. There were 85 respondents involved. The theory of fiber post was studied in fourth year of programme by $73.8 \%$ of respondents. $83.5 \%$ and $47.6 \%$ of respondents preferred to use fiber post for anterior teeth and posterior teeth respectively. About $83.5 \%$ of respondents agreed that post is indicated when there is only one third of tooth structure left, with $55.3 \%$ chose to place post within one week after semi-permanent restoration. Resin-based cement was the most preferred choice for cementation of fiber post (69.4\%). $92.9 \%$ of respondents used rubber dam isolation during post placement. The overall knowledge of respondents ranging from good to excellent was $61.2 \%$ to $20 \%$. Chi-square test was done and there was no significant correlation between practical hours and student's level of knowledge with p-value $>0.05$. There was no significant difference between total score and year of study by ANOVA test with p-value $>0.05$. This study showed good understanding and practice among undergraduate dental students in Universiti Sains Islam Malaysia (USIM) and other universities regarding their knowledge about fiber post.

Keywords: Endodontically Treated Tooth; Fiber Post; Knowledge; Undergraduate; Dentistry Students.

\section{Introduction}

Tooth that has been root-treated with minimal remaining tooth structure is indicated for coronal protection to give good longterm prognosis [1]. For this reason, intra-radicular post usage is commonly practiced by dentist to provide sufficient support and retention of the restoration. The post also allows build up and retain of coronal prosthetic core [2].

Other than the remaining tooth structure left (ferrule effect) and assessment of the endodontic status, other clinical factors such as the root anatomy, root length and its configuration, and occlusal forces need to be considered to prevent complication after post placement $[3,4]$.

Various techniques and materials were applied to aid restoring a tooth using a post and core. Advance dental materials technology introduced the pre-fabricated tooth coloured post such as fiber post which has given dentists additional advantages over the use of traditional cast metal posts or screw posts [5]. Moraes et al (2013) [6] stated that fiber posts are superior to metal posts as fiber posts are less likely to cause root fracture due to their lower modulus elasticity similarly to dentine and show similar stress patterns under external impacts. Fiber post is aesthetically beneficial especially for anterior teeth compared to metal post which can cause discolouration of the soft tissue adjacent to root surface

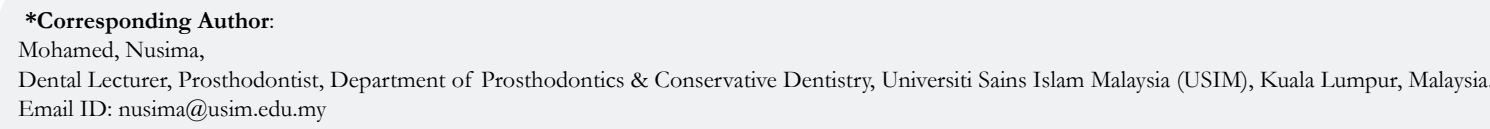

Citation: Mohamed, Nusima, Mohd Rasdi, Nurul Atiqah, Che Lah, Nur Fatin Izzati, Ismail, Nor Azlina. A Survey Of Knowledge and Clinical Consideration On Fiber Post For Restoration Of Endodontically Treated Tooth Among Undergraduate Dentistry Students. Int J Dentistry Oral Sci. 2021;08(03):2094-2098. doi: http://dx.doi.org/10.19070/23778075-21000413

Copyright: Mohamed, Nusima ${ }^{\circ} 221$. This is an open-access article distributed under the terms of the Creative Commons Attribution License, which permits unrestricted use, distribution and reproduction in any medium, provided the original author and source are credited. 
[7]. In contrast, fiber post for some reasons such as debonding or core fracture might be the reason of failure especially on anterior tooth as compared to cast metal post [6].

Due to a lot of considerations and factors to consider on post placement, there are confusion and disagreement of various components when considering post placement in clinical cases. There is no clear guideline for choosing the most appropriate system for a particular clinical situation [8]. The assumption is that the decision is influenced by the individual clinician's knowledge, experience, training and the resources available [9]. It is important to gather information from clinicians regarding their choice of post system to help understand and formulate appropriate guidelines for post core restoration placements especially during the training period of dentistry students.

In Malaysia, there is not enough documentation on the knowledge and practical training of fiber post on endodontically treated teeth by undergraduate dental students as basic data to produce guideline of tooth assessment for post and core. Therefore, this study aims to assess the student knowledge and their preference on fiber post placement according to the clinical situation.

\section{Materials and Method}

\section{Questionnaire development}

The questionnaire was designed to comprise three sections: (A) general information, (B) clinical knowledge assessment, and (C) clinical practice assessment. The general information section consists of seven details of respondents as shown in Table 1.

For section $\mathrm{B}$, questions were designed to get information on the level of basic knowledge on fiber post. Responses were by single or multiple answers to the options given. The questions are as listed in Table 2.

The section $\mathrm{C}$ consisted of ten anterior and occlusal view of the intra-oral clinical photos of a tooth indicated for fiber post and core were shown, and the respondents were asked to decide whether the tooth was indicated to place fiber post or not. All the questions were modified from a study by Weerapperuma et al. (2016) [10].

This questionnaire was validated by the prosthodontists in the universities and randomly selected undergraduate dentistry students to answer the questions.

\section{Survey distribution and inclusion/exclusion criteria}

The study received ethical approval from the Research Ethic Board, Universiti Sains Islam Malaysia (USIM) (USIM/JKEP/2019-54).

The questionnaire was conducted as an option-based online survey, self-administered Google Form method. A link was sent via e-mail to all undergraduate clinical dental students in USIM and six selected universities in Malaysia. Only the clinical dentistry students who had experience on fiber post placement at least once were included in this study. The students that has theoretically study fiber post however did not have experience on the post placement were excluded from this study. The students were asked to answer the questionnaire within 5 minutes once started and it is available online for one month.

\section{Data analysis}

The data was coded and entered into statistical software SPSS Statistics version 21.0 (IBM Inc. Chicago, IL). Descriptive analysis was carried out on all the questions showing either percentiles or frequencies. Correlation between two components was carried out using chi-square test of independence. ANOVA test was used to assess statistical relationship between a nominal variable and a continuous variable. Both of the statistical significance was set at $\mathrm{p}<0.05$.

\section{Results}

There were total of 87 respondents with $63(72.4 \%)$ female and

Table 1. The list of questions in section $\mathbf{A}$.

\begin{tabular}{|ll|}
\hline \multicolumn{2}{|l|}{ Section A: General information } \\
\hline - & Gender \\
\hline - & Age \\
\hline - & University \\
\hline - & Year of study \\
\hline - & Year of theoretical study \\
\hline - & Duration of clinical practice on fiber posts \\
\hline
\end{tabular}

Table 2. The list of questions in section $\mathrm{B}$.

\begin{tabular}{|c|c|}
\hline \multicolumn{2}{|c|}{ Section B: Clinically knowledge assessment } \\
\hline$\bullet \quad$ Indications for post placement \\
\hline$\bullet \quad$ Time to place a post \\
\hline & Type of post system used for anterior and posterior teeth \\
\hline & Type of fiber post system \\
\hline & Type of cement material used \\
\hline
\end{tabular}


$24(27.6 \%)$ male students. $77(88.4 \%)$ of the respondents studied at local universities while only $10(11.6 \%)$ were private university students.

Most of the students were in the final clinical year ( $n=68,78.0 \%$ ). Their practical sessions as well as the basic knowledge of post and core were learnt mostly in the second year of dental clinical training ( $n=63,73.7 \%$ ), few of them learnt it earlier in the first year of clinical training $(n=12,14.1 \%)$. However, there were 11 students $(12.8 \%)$ who learnt about post and core during their final clinical year.

The practical sessions were provided with one to three sessions which were equivalent to three to nine hours for practical of post as shown in Figure 1.

Table 3 presents the data on the respondents' basic clinical knowledge on post and core. On the tooth that was indicated for post and core, $81.6 \%(n=71)$ of respondents agreed that if a tooth just have only one third of coronal tooth structure left, it was indicated for post placement. Whereas 42 respondents $(48.3 \%)$ and $15(17.2 \%)$ agreed that post and core should be placed when only half of coronal tooth structure left and on all anterior endodontically treated tooth (ETT). treatment completed, $54 \%$ preferred to place post one week after semi-permanent restoration, $17.2 \%$ of respondents placed post immediately after obturation and $33.3 \%$ placed post and core after one month of endodontic treatment completed.

On the clinical procedures during post placement, the application of rubber dam was also asked. $93.1 \%$ of them applied rubber dam either by single or multiple isolation technique. Unfortunately, there was still small portion of them $(6.9 \%)$ who did not use rubber dam during the procedure. For type of cement use to cement fiber post, resin-based cement was the most favourable choice among the respondents $(67.8 \%)$.

Data in Figure 2 showed the preferred type of post use for endodontically treated tooth (ETT) anterior or posterior tooth. About $89.6 \%$ of respondents preferred to use fiber reinforced post for selection of post system on anterior tooth while for posterior tooth, metal post $(53.5 \%)$ was more preferable than fiber reinforced post $(46.5 \%)$.

For the data analysis, the respondents' answers in section B and C were given scores to assess their level of knowledge which showed that most respondents have good understanding on post and core indication, type, cement used and standard procedure (Figure 3).

For the time recommended for post placement after endodontic

Table 3. Percentage of the responses given for the component of question asked in the basic clinical knowledge section of the questionnaires.

\begin{tabular}{|c|c|c|}
\hline Questions & Answer options & Number of respondents (\%) \\
\hline \multirow{4}{*}{\begin{tabular}{c} 
Tooth indicated for post \\
\cline { 2 - 2 } $\begin{array}{c}\text { Time recommended for post } \\
\text { placement on ETT }\end{array}$
\end{tabular}} & All anterior root treated teeth & $15(17.2 \%)$ \\
\cline { 2 - 3 } & Half of coronal tooth structure left & $42(48.3 \%)$ \\
\cline { 2 - 3 } & One third of coronal tooth structure left & $71(81.6 \%)$ \\
\cline { 2 - 3 } & Immediately after obturation & $15(17.2 \%)$ \\
\cline { 2 - 3 } $\begin{array}{c}\text { Rubber dam application during } \\
\text { post placement }\end{array}$ & More than 1 month semi-permanent restoration & $47(54.0 \%)$ \\
\cline { 2 - 3 } & Yes, single isolation & $29(33.3 \%)$ \\
\cline { 2 - 3 } & Yes, multiple isolation & $11(12.6 \%)$ \\
\hline \multirow{3}{*}{$\begin{array}{c}\text { Cement usemi-permanent restoration } \\
\text { me for fiber post ce- } \\
\text { mentation }\end{array}$} & No & $10(11.5 \%)$ \\
\cline { 2 - 3 } & Resin based cement & $6(6.9 \%)$ \\
\cline { 2 - 3 } & Glass ionomer cement & $59(67.8 \%)$ \\
\cline { 2 - 3 } & Zinc phosphate & $25(28.7 \%)$ \\
\hline
\end{tabular}

Figure 1. Hours and frequency of practical session provided for post and core.

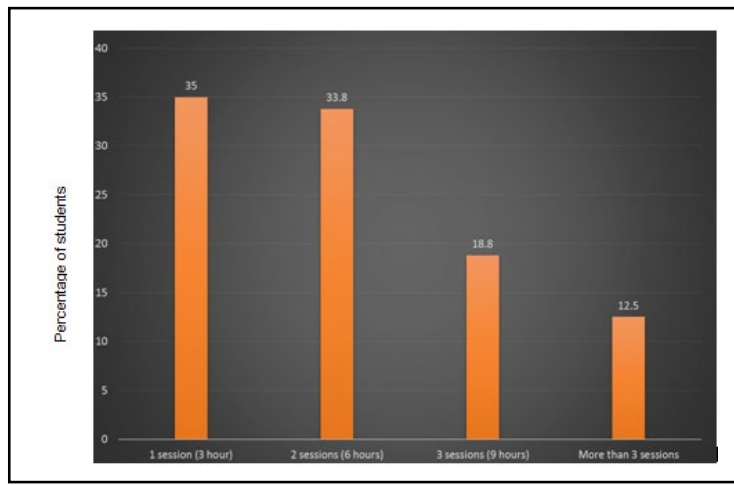


Figure 2. Graph of the percentage of the respondents' responses to the type of post preferred for an endodontically treated tooth (ETT) for anterior and posterior teeth.

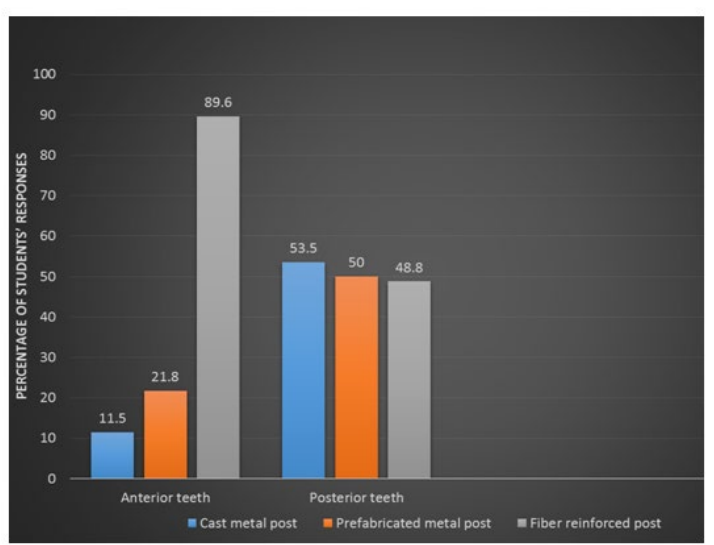

Figure 3. Number of respondents with total score of the answers in section $B$ and $C$ of the questionnaires.

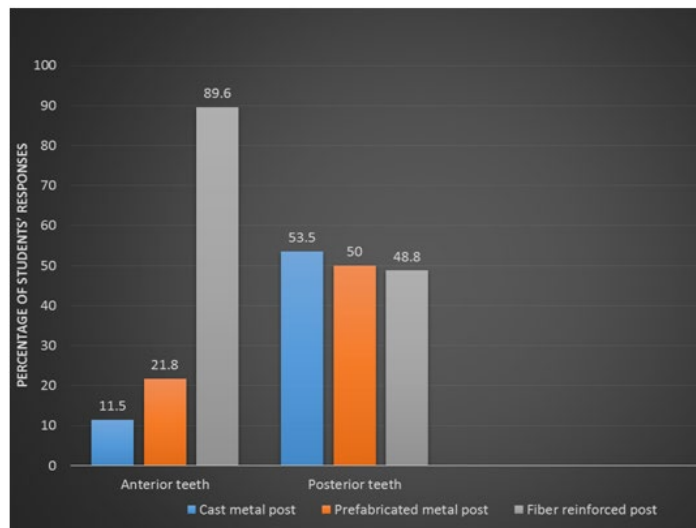

\section{Discussion}

From this study, it was found that there was no significant relationship between hours of practical sessions and level of knowledge of the students on post and core with ( $p$-value $>0.05)$. This implies that practical sessions of three to nine hours were enough to expose the undergraduate students to post and core knowledge and the procedures involved.

There was also no significant difference (with $\mathrm{p}$-value $>0.05$ ) on the year of study of post and core, and the students' level of understanding of indications for post and core. However, as most of the students have had their practical sessions and basic knowledge on post and core exposure in the second year of clinical training it is advisable that this curriculum is continued. By doing this, the level of basic knowledge understanding on post and core can be maintained due to continuously and directly applied to the clinical experienced when they practice post and core clinically during the clinical years.

It has been well known that the endodontically treated tooth (ETT) is most likely to be placed with post and core prior to the construction of permanent restoration such as crown. Dikbas et al (2013) [9] stated that many studies have reported on the success rate, guideline for post placement and type of post used for ETT. However, there is no proper guideline on the process on how to choose suitable tooth for certain post system. This study helped to assess the dentistry curricula on post and core training as for now fiber post is one of the most commonly used post for ETT especially for anterior teeth. It is important to make sure students really understand indications and sensitive operative technique conducted during the placement of fiber post on ETT due to its failure mostly due to debonding and incorrect clinical assessment tooth suitable for fiber post $[6,11,12]$.

An analysis showed that for anterior teeth, students prefer to choose prefabricated posts $127 \%$ more than the dentists while for posterior teeth, students less prefer to choose prefabricated posts $40 \%$ compared to dentists [13]. Our study also found the same results where the respondents chose fiber reinforced post (prefabricated post) for anterior teeth and metal cast post for posterior teeth. This is mainly due to the recent developments in the field of aesthetic dentistry. Tooth coloured endodontic post has served to provide an aesthetically pleasing and easily retrievable post by serving to provide an ideal endoesthetic restorative continuum comprising of an aesthetic non-metallic post, a composite core and a dual cure resin luting cement especially at anterior tooth $[2,14]$.

Furthermore, fiber post has greater clinical performances in term of modulus of elasticity which is similar to dentin. The fact that most of universities nowadays tend to teach fiber post rather than metal cast also becomes one of the reasons for preference for fiber post. Further study on this topic will hopefully turn up the rationales and guideline for better success rate of a fiber post on anterior ETT especially those with minimal remaining tooth structure that requires post to retain the core. Our study showed that students know that only the tooth that has minimal tooth structure left (half to one third crown left) needs post and core. 
There are factors that can influence the survival of intraradicular post system such as the ferrule effect and post-related factors. These are the decisive factors for the success of cast post and core. Study by Sarkis-Onofre R et al (2015) [15] also showed that experience is not the main factor of the failure of post and core; but the procedures such as rubber dam placement and following the correct technique of cementation, and the cement used for post cementation leads to the success of fiber post and core. In our study, undergraduate dentistry students have good understanding of the correct techniques on the procedure of post placement. However, retrospective study should be done to assess success rate of fiber post placement by undergraduate dental students in Malaysia.

Some clinical study stated that separation of post is the most common failure of post-based restorations. Specifically for endodontic tooth with fiber post, the tooth failure is usually associated with debonding of post from tooth, post-traumatic fracture and build up core fracture. Moreas et al. (2013) [6] suggested that in order to reduce the occurrence of root fractures or post debonding, resin composite type of cements is highly recommended to bond fiber post intra-radicularly. Our study showed that the undergraduate students use only resin-based cement $(67.8 \%)$ or tooth bonded cement such as glass ionomer cement and resin modified glass ionomer cement to cement fiber post in order to confirm the success.

The use of online questionnaire can lead to low response rate. Although this questionnaire can reach all dentistry schools in Malaysia, the number of respondents is quite low. A survey with larger sample size and more defined comparison groups may yield a more conclusive outcome. In addition, a longer period of availability of the questionnaire may increase the responses rate.

In the future, we would like to suggest for a retrospective study to be done on the success rate of fiber post between undergraduate and postgraduate dentistry students, specialists and general practitioners in Malaysia to see any statistically significant difference between those groups.

\section{Conclusion}

This study has shown good understanding and practice among undergraduate dentistry students regarding their knowledge about fiber post placement. They have good knowledge on choosing suitable post system and chose correct techniques and procedures for fiber post placement. They are also able to determine the indications for fiber post placement.

\section{Acknowledgment}

The authors wish to thank Universiti Sains Islam Malaysia (Grant code: PPPI/KHAS_FPG/051007/14719) and Faculty of Dentistry, Universiti Sains Islam Malaysia for providing the financing and facilities.

\section{References}

[1]. Zarow M, Ramírez-Sebastià A, Paolone G, de Ribot Porta J, Mora J, Espona J, et al. A new classification system for the restoration of root filled teeth. Int Endod J. 2018 Mar;51(3):318-334. Pubmed PMID: 28853160.

[2]. Alhashim NS, Al-Moaleem MM, Al-attas HA. Tooth Colored Post System: Review of Literature. International Journal of Contemporary Dentistry. 2013 Mar 8;4(1).

[3]. Juloski J, Radovic I, Goracci C, Vulicevic ZR, Ferrari M. Ferrule effect: a literature review. Journal of endodontics. 2012 Jan 1;38(1):11-9.

[4]. Zicari F, Van Meerbeek B, Scotti R, Naert I. Effect of ferrule and post placement on fracture resistance of endodontically treated teeth after fatigue loading. Journal of Dentistry. 2013; 41(3):207-15. Pubmed PMID: 23069329.

[5]. Lamichhane A, Xu C, Zhang FQ .Dental fiber-post resin base material: a review. The journal of Advanced Prosthodontics. 2014; 6(1):60-5. Pubmed PMID: 24605208.

[6]. de Moraes AP, Cenci MS, de Moraes RR, Pereira-Cenci T. Current concepts on the use and adhesive bonding of glass-fiber posts in dentistry: a review. Applied Adhesion Science. 2013 Dec;1(1):1-2.

[7]. Bru E, Forner L, Llena C, Almenar A. Fibre post behaviour prediction factors. A review of the literature. J Clin Exp Dent. 2013 Jul 1;5(3):e150-3. Pubmed PMID: 24455071.

[8]. Naumann M, Neuhaus KW, Kölpin M, Seemann R.Why, when, and how general practitioners restore endodontically treated teeth: a representative survey in Germany. Clinical Oral Investigations. 2016; 20(2):253-9. Pubmed PMID: 26082310.

[9]. Dikbas I, Tanalp J. An overview of clinical studies on fiber post systems. ScientificWorldJournal. 2013 Oct 23;2013:171380. Pubmed PMID: 24250255 .

[10]. Weerapperuma ID, Taylor C, Satterthwaite JD. A survey to compare the use and rationale for selection of intra-radicular posts among dental practitioners. Br Dent J. 2016 Nov 18;221(10):635-638. Pubmed PMID: 27857115.

[11]. Goracci C, Ferrari M. Current perspectives on post systems: a literature review. Aust Dent J. 2011 Jun;56 Suppl 1:77-83. Pubmed PMID: 21564118.

[12]. Liu C, Liu H, Qian YT, Zhu S, Zhao SQ () The influence of four dual-cure resin cements and surface treatment selection to bond strength of fiber post. International Journal of Oral Science.2014;6(1):56-60. Pubmed PMID: 24177170.

[13]. Sedrez-Porto JA, Sarkis-Onofre R, Moraes AP, Correa MB, Cenci MS, Pereira-Cenci T. Knowledge and attitudes of students and dentists about the use and cementation of intra-radicular posts. Brazilian Dental Science. 2017 Dec 15;20(4):93-9.

[14]. Sneha P, Nivedhitha MS, Adimulapu HS .Evaluation of Different Post Endodontic Restorations used in Endodontically Treated Maxillary and Mandibular Anteriors - An Institution Based Retrospective Study. Int J Dentistry Oral Sci. 2020;S10:02:006:31-37.

[15]. Sarkis-Onofre R, Pereira-Cenci T, Opdam NJ, Demarco FF. Preference for using posts to restore endodontically treated teeth: findings from a survey with dentists. Brazilian oral research. 2015;29(1):1-6. 